\title{
Is transport subcontracting a barrier to modal shift? Empirical evidence from Germany in the context of horizontal transshipment technologies
}

\author{
Eugen Truschkin • Ralf Elbert • Armin Günter
}

Received: 12 December 2012/ Accepted: 14 October 2013/Published online: 13 May 2014

(C) The Author(s) 2014. This article is published with open access at Springerlink.com

\begin{abstract}
Guided by the theory of organizational path dependence, this paper explores whether transport subcontracting might be a barrier to modal shift from road transport to combined transport if access to combined transport is enabled by horizontal transshipment technologies. In this paper, we attempt to evaluate the path dependence of two different groups of forwarders based on the quantitative data derived from web-based questionnaires conducted in Germany in the spring of 2011. We find that the willingness to shift transport modes is significantly higher if forwarders use their own semi-trailers rather than subcontracting with a transport fleet. Our study contributes to the literature by providing an empirical investigation into the building of organizational paths.
\end{abstract}

Keywords Modal shift - Combined transport - Horizontal transshipment · Subcontracting · Organizational path dependence

JEL Classification L91 $\cdot$ D22 - O33

Responsible editor: Karl Inderfurth (Operations and Information Systems).

E. Truschkin $(\square) \cdot$ R. Elbert

Chair of Management and Logistics, Technische Universität Darmstadt, Darmstadt, Germany

e-mail: truschkin@bwl.tu-darmstadt.de

R. Elbert

e-mail: elbert@bwl.tu-darmstadt.de

A. Günter

Business Excellence DB Schenker, DB Mobility Logistics AG, Berlin, Germany

e-mail: armin.guenter@deutschebahn.com 


\section{Introduction}

It is acknowledged that freight volume will continue to show significant growth in the coming years. Rich and Hansen (2009) expect that the total transport performance in road freight transport (RFT) in the EU 27 will increase to 2442 billion ton-kilometers (tkm) by 2030, which is $43 \%$ greater than it was in 2005. In another important worldwide road transport market, that of the U.S., the total road freight tonnage is expected to grow by $21 \%$ by 2023 (American Trucking Associations 2012). Because of the increasing congestion on public highways and as a result of increasing environmental awareness, the significant growth in the transport volume of RFT is considered particularly critical. Therefore, one of the current objectives of the EU transport policy is to shift more than $50 \%$ of the RFT to waterborne or rail transport for longer distances $(>300 \mathrm{~km})$ (European Commission 2011). Because $70 \%$ of the total RFT performance-approximately 229 billion tkm-was produced by means of semi-trailers in Germany in 2011 (Federal Motor Transport Authority 2012), semi-trailers can be considered to be the primary intermodal transport unit for producing a significant modal shift from road to rail. In intermodal transport, goods are transported in one and the same loading unit or road vehicle, "which uses successively two or more modes of transport without handling the goods themselves in changing modes" (UN/ECE 2001). However, only the minority of semi-trailers (up to $5 \%$ ) are liftable and, thus, accessible to the existing continental combined freight transport (CCFT) system. Combined transport is a special form of intermodal transport, and it is defined as " "...intermodal transport where the major part of the European journey is by rail, inland waterways or sea and any initial and/or final legs carried out by road are as short as possible", (UN/ECE 2001).

Consistent with the objectives of transport policy, there are a variety of technology providers who offer solutions for the horizontal transshipment of nonliftable semi-trailers (e.g., CargoBeamer ${ }^{\circledR}$, Modalohr, Mega Swing by Kockums Industrier). In recent years, accelerated marketing efforts from several technology providers who strongly advocate for horizontal transshipment technologies for nonliftable semi-trailers in the transport market have been observed. On contrast to vertical transshipment, which is performed by portal cranes, horizontal transshipment technologies operate with rotating or sliding wagon elements. Thus, the semitrailers need not to be equipped with the special grappler pockets that containers require. The figures above illustrate the market potential that "theoretically" could be shifted from road to rail if the access barrier to the CCFT system is overcome as a result of these new technologies. Therefore, horizontal transshipment technologies maybe perceived as a powerful enabler for the modal shift from road to rail.

Concerning the choice of transport mode, the forwarder can be considered the final decision maker if this is where the organization of the transport service has been outsourced to (Bergantino and Bolis 2004). Arguably, however, the forwarder's economic choices do not always correspond to policy objectives and technology developments (Chiara et al. 2008). Hence, investors in the horizontal transshipment technologies require prior knowledge of the freight transport demand (Feo et al. 2011), thereby allowing the investors to address high demand market 
segments with combined transport mode. Because there are several types of players in transport chains, each with their own set of objectives and means (Crainic and Laporte 1997), the demand estimation approaches in the transportation market should address, along with the specifics of the transport modes, the characteristics of the decision makers (Tsamboulas et al. 2007). However, there are a few papers that specifically address the heterogeneity of the demand side (decision makers) in choice of transportation mode (see, for example, Danielis et al. 2005; Tsamboulas et al. 2007; Eng-Larsson and Kohn 2012). The only work that could be identified relating to market acceptance for the new transshipment technologies was conducted by Chiara et al. (2008). This paper shows that Modalohr, as a specific form of horizontal transshipment technology, would increase the attractiveness of combined transport for decision makers, especially in the case of better scheduling of mandatory rest hours and increased service frequency. Chiara et al. (2008) also emphasize the importance of the company's organizational structure in the choice of CCFT to guarantee the rolling off of the semi-trailer once it is unloaded from the train. However, the detailed investigation of the impact of the characteristics of forwarders is not within the research scope of the work. Nonetheless, in many cases, the freight forwarders operate contracted road haulage fleets (Anderson 2010), causing them to be less neutral when making decisions regarding transportation modes (Vassallo et al. 2007). Therefore, due to the possible impact of the current organizational disposition form of the forwarder, namely, operating with his own or with a subcontracted fleet, it can be suggested that the elimination of the access barrier to the CCFT through the horizontal transshipment technologies does not lead "automatically" forwarders to make a modal shift. Consequently, the unit of analysis of the present study builds the sub-network between forwarder and road hauler which, in turn, is a part of an inter-organizational supply network in the road transportation chain.

Based on the theory of organizational path dependence (Sydow et al. 2009), this study examines whether transport subcontracting might be a barrier to modal shift from road transport to combined transport if access to combined transport is enabled by horizontal transshipment technologies. More generally, our primary research question can be expressed as follows: Which factors of inter-organizational networks in road transport, specifically, in the forwarder-road hauler relationship, can be considered to be barriers to the modal shift from road to rail?

In this context, we attempt to evaluate the path dependence of two different groups of forwarders based on quantitative data. For this purpose, two web-based questionnaires, one for forwarders and one for road haulers (i.e., the subcontractors of the forwarders), were administered in Germany in spring 2011 to investigate the possible impact of the disposition form on the willingness to shift modes. Because of the significant volume of RFT (313 billion tkm in 2010) generated in Germany (Eurostat 2011), we determined that Germany provided an acceptable setting for our research.

The paper is structured as follows. In Sect. 2, different contractual forms in road freight transportation and the organizational barriers to modal shift are presented. The research propositions are also derived in this Section. The methodology of data collection is presented in Sect. 3, and Sect. 4 presents and discusses the empirical 
results. The paper concludes with final remarks, practical implications, the paper's contribution to the literature and recommendations for future research.

\section{Heterogeneity on the demand side and its impact on the choice of transport mode}

\subsection{Contractual forms in road freight transport}

The producers of the goods that determine the demand for transportation are often called shippers, while the transport companies that perform the transportation can be subsumed under carriers (Crainic and Laporte 1997). In addition to road haulers or railway operators, freight forwarders can be classified as carriers, as they not only operate in their classic role as an intermediary, but because they have their own transportation assets, they also act as both forwarders and transport haulers (Woxenius and Bärthel 2006: 16). Moreover, to achieve competitive rates, most of the freight forwarders hold contracts with other transportation companies, making them less neutral when making decisions regarding transport modes (Vassallo et al. 2007).

In this paper, we concentrate on forwarders, who are the decision makers with respect to the transportation mode. This decision represents a response to the previous studies by Feo et al. (2011) and Bergantino and Bolis (2004) and had the following reasons. Often companies delegate the transport organization and consequently the mode decisions to forwarders to benefit from their specific know-how in the transport market. Forwarders can supply the shippers with attractive transport offers by their ability to organize the transport more efficiently (e.g., through bundling consignments and minimizing empty trips and the selection of the appropriate transport mode and the corresponding subcontractor). That is, the transport organization represents the core competence of forwarders. According to a recent third-party logistics study, the majority of shippers $(65 \%)$ continue to increase the use of third-party services and term their relationships with 3PLs (thirdparty logistics) successful, crediting them with providing new and effective ways to improve logistics effectiveness (Langley 2013). Of all the services outsourced to 3PLs, transportation represents the largest sector (76 \% of international and $71 \%$ of domestic transport services across all the regions studied are outsourced) (Langley 2013). Despite the predominant role the forwarders play in the transport organization, they continue to be affected by the cost and quality requirements of the shippers (Sommar 2006). Nevertheless, if the transport is outsourced to a forwarder, the forwarder can be considered to be the final decision maker in the mode choice (Bergantino and Bolis 2004).

The shipper can perform the transport independently, directly hire the road hauler or task the forwarder with transporting the goods. In the latter case, the forwarder can be faced with a "make-or-buy" decision, that is, to use his own vehicles (given he owns transportation assets) or to act as an intermediary (Krajewska and Kopfer 2009). When acting as an intermediary, the forwarder can operate the contract with another forwarder, or he can hire the road hauler to perform the transport. Hence, in 
the present work, two general disposition forms in the forwarder's company-selffulfilling and subcontracting-are identified. One way to hire subcontractors is through spot market Internet platforms (e.g., Logintrans, TimoCom) that bring the supply side together with the demand side. However, spot transactions are not within the scope of our work because they rarely involve long-term relationships with the supplier (Kaplan and Sawhney 2000) and are primarily used if the current demand cannot be satisfied by the subcontractors on a long-term basis (Jurczyk et al. 2006). Consequently, a long-term partnership is another way to employ subcontractors. As the average duration of a partnership in road-based networks is 7.6 years (Schmoltzi and Wallenburg 2010), the character of the long-term relationship between two parties can be considered as closer and more integrated than those in spot market contracts. Based on the framework developed by Zinn and Parasuraman (1997), the relationship between forwarder and road hauler maybe regarded as a focused relationship. Such an alliance is characterized by a strong commitment of the resources necessary to implement and perform a limited number of services. Consequently, forwarders in the road transport sector cannot be considered to be autonomous entities (Gulati et al. 2000) but part of a supply network that starts with the shipper and ends with the receiver. The relationship between forwarder and the road hauler, which is the focus of the present study, creates a sub-network and is broadly applied in the road transportation market, as demonstrated in Sect. 3.2.

The next Section provides a detailed overview of the impact of the different disposition forms on the transport mode decision making followed by the derivation of the research propositions.

\subsection{Organizational barriers to modal shift and the research propositions}

According to the current Association Materials Management, Purchasing and Logistics (AMMPL) survey, the low flexibility level of railroads, the lack of siding track and the low level of customer service are the primary reasons for the underuse of rail services (Wittenbrink 2009). In the AMMPL survey, 171 respondents from different industry sectors in Germany indicated low company freight volume, expensive rail transportation, short distances, complicated billing processes, and the lack of rail service in the portfolio of logistics providers as the barriers to the company's use of rail transport (Wittenbrink 2009). However, in the AMMPL survey, the organizational capability to use rail transport was not investigated.

According to Behrends (2011:34), the implementation problems of the CCFT system are often attributed to both technological and organizational complexity of this transport mode. Thus, the additional expenses in the transport organization, which should be overcome by the decision to select this transport mode, can be considered to be a barrier to modal shift. Because of the diversity of actors, each of whom organizes and controls part of the transport chain, the level of complexity in the CCFT system is higher than in unimodal transport modes (Bontekoning et al. 2004). In the CCFT system, the following components can be distinguished: preand post-carriage by the road transport (collection and distribution from shippers to receivers), the exchange of loading units at the intermodal (rail/road) terminals and 
the rail line hauling (main haul) (Janic 2008). In contrast to studies that investigate shippers as decision makers in the transport mode choice, the present study focuses on freight forwarders. The decision to concentrate on forwarders was based on the following reasons. With an increasing tendency to outsource, companies delegate transport organization and mode decisions to third parties who make it possible to benefit from the forwarder's knowledge and skills of the specific transport market (Bergantino and Bolis 2004). Regardless whether the forwarder's disposition form is self-fulfilling or subcontracting, an adaptation in the organizational routine maybe necessary for CCFT to be considered to be a transport mode option. In the event that a forwarder decides to use CCFT, he must organize the transport chain, which consists of the pre- and post-carriage and main haul, and he must work together with the actors in the particular subsystems (road hauler, intermodal transport operator, intermodal terminal provider) (Ishfaq and Sox 2010). Depending on the current disposition form, specific barriers for the decision to use a CCFT system can arise. However, in both cases, the contractual agreements with other forwarders or road haulers are necessary to organize the post-carriage of transport (Chiara et al. 2008). In addition, the issue of how to organize the return transport of the disposed semitrailer must be addressed. Particularly in cases of transport subcontracting, additional barriers may occur. If the forwarder decides to dispose the semi-trailer in the CCFT by keeping the contract with the current road hauler, the road hauler must change his business model and shift from long distance operations to operations in the pre- or post-carriage. Consequently, in contrast to RFT, the forwarder in the CCFT system must take control over the semi-trailer of the road hauler to ensure the post-carriage and return transport while also considering the business interests of the partner in the business model change. The demonstrated changes in the set of organizational routines that are required for the shift from RFT to CCFT can result in additional expenses for the transport organization, thus becoming a potential barrier to the modal shift. This is especially true in the case of transport subcontracting where the willingness to shift to combined transport maybe lower than in the case where the forwarder has his own fleet. In the following, the theoretical underpinnings that explain the expected forwarder's behavior are developed.

According to Kim et al. (2006), previous research has paid insufficient attention to constraints on network change that impact the current partner's ability to access the resources of the new partners. The authors believe that this lack of attention is because the organizational theories share an adaptation perspective regarding changes in the organization. From this perspective, inter-organizational networks are assumed to be flexible enough to be created and manipulated at little cost. Accordingly, network change is not considered an obstacle (Kim et al. 2006). However, a firm's early partner choices have a significant impact on the course of future cooperation (Walker et al. 1997). The choices made by a focal actor in any given period can lock the firm into or out of certain alliance choices where it is neither easy nor cost-free to shift across network sub-groups (Gulati et al. 2000). More generally, a chosen solution cannot arguably be amended without additional costs or without incurring some "sunk costs" (Koch 2011). The organization's initial investments are often perceived as a reason for such a historically induced 
restriction (Arrow 2004: 24; Wilson 1995; Warning 2004). As most of the roadbased network cooperation is long-term, forwarders may tend to maintain consistency in organizational action due to insufficient knowledge regarding the inter-organizational network change, which Khanna (1998) defines as "alliance capability". According to Khanna (1998), an alliance capability is a “firm's ability to identify partners, initiate alliances, and engage in the ongoing management and possible restructuring and termination of these alliances". Furthermore, once relationship-specific routines, such as certain technology-based rules or embedded cultures, become institutionalized between two parties, it is unlikely that the firms will replace their partners with new ones based solely on economic motivations. That is, "network inertia" can occur (Kim et al. 2006). Under specific circumstances, such a behavior of forwarders can be considered to be path dependent.

The theory of organizational path dependence postulates that organizations can lose their flexibility and become inert or even locked in (Sydow et al. 2009). This theory stresses the impact of past events, often captured in the phrase "history matters", for current and future decision making (Sydow et al. 2012). That is, although in the initial phase, the decision-making processes are open so that the choice between several alternatives is possible, over time, the number of possible alternative courses of action decreases rapidly until an organization is "locked in". Thus, the process of becoming path dependent is framed as a process of increasing reduction in a range of choices that hinders an organization in its ability to act strategically and to survive in a competitive environment (Koch 2011). In contrast to the broad application of path dependence theory in the research field of technology and innovation management (Schreyögg and Sydow 2011), a more rigorous and conceptual understanding of organizational path dependence is still part of a nascent field of management and organization research (Koch 2011).

The logic of entrapping processes can be explained by one or a combination of several self-reinforcing social mechanisms. After being initiated, these mechanisms sustain the contingently selected path (Vergne and Durand 2011). Sydow et al. (2009) argue that coordination effects, complementarity effects, learning effects, and adaptive expectation effects are likely to contribute to the development of organizational path dependence. Vergne and Durand (2011) argue that the selfreinforcement may consist of positive mechanisms that directly support the chosen path and negative mechanisms that indirectly sustain the chosen path, render alternative paths less attractive. Contrary to Sydow et al. (2009), the latter mentioned authors' pay significant attention to the importance of the negative mechanisms in the evolution of path dependence. Accordingly, this paper assumes that path dependence is less about how actual paths are selected and more about how alternative paths are deselected. Although the mechanisms presented by Sydow et al. (2009) are based on the conception of increasing returns (Arthur 1994) and a broad range of positive feedback (Beyer 2010), they can also be considered from the perspective of the negative externalities. For example, positive feedback regarding the learning effects of selected alternative also decreases the probability that an alternative path will be selected. Consequently, there is always another side to the positive mechanisms - the negative effects side (Vergne and Durand 2011). Hence, 
in the present contribution, the self-reinforcement mechanisms presented by Sydow et al. (2009) are adopted because they can be considered from both perspectives.

Complementary effects explain the organizational path dependence through advantages of economies of scope-the synergy that results from the interaction of two or more separate but interrelated resources, rules, or practices (Stieglitz and Heine 2007) — which appears to be less applicable to the inter-organizational relationship between the forwarder and the road hauler when the assets of both parties are not complemented. That is, in the investigated problem, the forwarder uses the assets of the subcontractor. With respect to our research question, the coordination effects, the learning effects and the adaptive expectation effects appear to be the major motivators for the forwarder's expected decision behavior.

Coordination effects result from the benefits of following the same single rule or set of related rules to which others are willing to conform. The more actors who follow the defined rules, the more effective the interactions among these actors, as the behavior of other actors can be anticipated and the reactions can be considered in advance (Schreyögg and Sydow 2011). Furthermore, as coordination costs can be significantly reduced, a specific pattern of practices is likely to become fixed (Sydow et al. 2009). The above-mentioned authors emphasize the fixing power of such patterns noting the examples of Polaroid and newspaper companies, where organizational members have recognized new challenges but failed to change their practices because they could not diverge from their well-attuned routines. In other words, once an organization has adopted a set of routines, it is difficult to change these routines (Koch 2011).

Learning effects are gained through subsequent iterations of an operation, resulting in the increase of operational efficiency. The more attractive the chosen solution becomes due to accumulated skills and decreasing costs, the less attractive it becomes to switch to an alternative (Sydow et al. 2009). In addition, it is the aim of many organizations to maintain their "core competence" (Prahalad and Hamel 1990), that is, a set of successful strengths that tends to focus all learning abilities on refining this success. The learning effects are acquired in a specific field of practices and cannot be easily transferred to a new alternative. Therefore, the motivation to look for additional alternatives and to critically examine the established organizational practices is likely to decline progressively over time. Thus, it is argued that core competences and capabilities that develop over time always result in organizational inertia (Leonard-Barton 1992; Miller 1993). On the other hand, it is argued that it is rational to follow the path because the developed strategic pattern gains positive feedback (Koch 2011). According to Vergne and Durand (2010), the positive outcome for a firm of the path-dependent capability is more likely when asset complementarities, learning specialization, or increasing returns to scale and scope prevent imitation by the firm's competitors.

The adaptive expectation effects focus on individual preferences that vary in response to the expectations of others (Schreyögg and Sydow 2011). Sydow et al. (2009) explain that because users are often uncertain regarding the correct choice, they feel assured that others are likely to prefer the same. It can, therefore, be concluded that the willingness to adopt the new practice decreases if users do not expect others to adopt it. 
The initial investments in the fleet of the non-liftable semi-trailers allow their usage solely in this transport mode. The reasons for forwarders to invest in nonliftable semi-trailers include a higher payload $(200-500 \mathrm{~kg}$ ) and, more relevantly, lower costs (CargoBeamer 2013). In contrast, to increase the attractiveness of investing in liftable semi-trailers, several policy incentives were introduced. Semitrailers that are used in CCFT were allowed to transport $44 \mathrm{t}$ rather than $40 \mathrm{t}$ in the RFT ( $\$ 34$ par. $6 \mathrm{StVZO}$ ) and were exempted from the road vehicle tax ( $\$ 3$ par. 9 $\mathrm{KraftStG})$. In addition, road pre- and on-carriage were exempted from the weekend and holiday driving ban ( $\$ 30$ par. 3 StVO). An additional advantage of CCFT-use for semi-trailers is the possible abolishment of the European Economic Community (EEC) regulation no. 3820/85 on driving hours and rest periods, which is applied across the European Union. According to this rule, the driver must have rest for $45 \mathrm{~min}$ after each $4.5 \mathrm{~h}$ of driving. Moreover, after a driving period of $9 \mathrm{~h}$, an $11 \mathrm{~h}$ rest period must be taken. Because the main run in the CCFT is performed via rail to limit the pre- or post-carriage to as short a time as possible (UN/ECE 2001: 18), the EEC regulation is not applied.

In addition, over time, forwarders have adopted a set of routines for increasing the coordination efficiency between the participating actors (forwarder and road hauler), and they have also acquired the know-how in the transport area of RFT, as evidenced by the positive feedback from the learning effects. According to the Transportation Research Board (1996:4), a modal orientation is endemic to most transportation organizations that have historically strengthened their core competence by reinforcing the importance of their particular mode and organizational purpose. Thus, even if a CCFT system maybe competitive with RFT in terms of, e.g., transport cost or transport time, the positive feedback from RFT in terms of well-developed coordination routines and the specific know-how gathered over the years in RFT produce negative externalities for not selecting the alternative path, that is, the CCFT. Due to the additional coordination expenditures in the case of subcontracting resulting from acting as an intermediary between the road hauler and other actors of the subsystems of the CCFT system (Behrends 2011:34; Bontekoning et al. 2004), it can be expected that companies that predominantly hire subcontractors in the present can show increased persistence in the accepting of CCFT. These additional coordination rules may also cause subcontractors to be unwilling to shift from long runs to operations in pre- or post-carriage. Expecting the unwillingness of subcontractors to follow new rules, the forwarder may also demonstrate an unwillingness to choose CCFT. Therefore, the evaluation of expected road hauler behavior for the decision of the forwarders is indispensable for the following development of the central proposition P5. Hence, we formulate the following proposition for the exploration of the willingness of road haulers to change the business model:

P.1: A road hauler would shift from long distance to pre- or post-carriage if the forwarder expects this behavior from the road hauler.

In addition, the negotiation power (bargaining position) of road haulers is valuable for the investigation to detect whether the road haulers, from their own perspective, can influence the strategic choices of forwarders and, consequently, 
impact the creation of new coordination rules. The strong negotiation power of road haulers would hinder forwarders from promoting the new rules and could be considered to be a reason why road haulers would not change their business model. In this context, the stronger bargaining position of the truck owners, in contrast to that of the forwarder company's drivers, in terms of contract negotiation, was highlighted by Nickerson and Silverman (2003). According to these researchers, it is less expensive for a forwarder to replace a company driver than to replace an owner-operator because of a pre-existing dependence on the assets of the truck owners (Nickerson and Silverman 2003). Thus, it maybe expected that road haulers as asset owners may influence the strategic choices of forwarders. The negotiation power is reflected in the second proposition:

P.2: Road haulers' negotiation power with the forwarders is low, as the road hauler fulfills the orders and cannot influence the strategic decisions of the forwarder (e.g., the decision to shift the transport mode).

If the road hauler decides to shift the business model from long runs to operations in the pre- or post-carriage, two possible fleet strategies for road haulers can be pursued. In the first alternative, after unloading the commodity of the customer, the semi-trailer can be hauled away immediately to a pool of semi-trailers located at an intermodal terminal, analogous to the container-pool, or it can be transferred to the next demand customer of the semi-trailer (Choong et al. 2002). In the second alternative, the semi-trailer pool is not embedded, and thus, the transport ends in the reception area of the last receiver (Janic 2007), which can either be the next demand customer or the road hauler. In this situation, the semi-trailer remains the property of the road hauler. Hence, the first fleet strategy is expressed as follows:

P.3: The road hauler keeps the semi-trailers and entrusts other companies to use them (e.g., for the main haulage or post-carriage). At the same time, the road hauler will operate semi-trailers of other companies (e.g., in the postcarriage).

The second fleet strategy is formulated as follows:

P.4: The road hauler sells the semi-trailers to the semi-trailer pool and makes use of the pool. Consequently, the fleet of road haulers will only consist of the trucks.

With the propositions P.3 and P.4, we attempted to gain an insight into the possible fleet strategies of road haulers. The issue of what should occur with the semi-trailers in the course of the shift to CCFT is not addressed in the current literature. However, in our opinion, the fleet strategies represent a cornerstone of the acceptance of the CCFT by road haulers.

Due to the higher coordination expenditures, the forwarders maybe less willing to shift to the new mode than will those forwarders who use their own fleet. In combination with the negative externalities for RFT, which result from the coordination and learning effects, forwarders operating by means of subcontracting maybe less inclined to leave their well-attuned practice and to shift the semi-trailers of the subcontractors (road haulers) to the CCFT system. In addition, because of the 
expected coordination expenditures for both parties (the forwarder and the road hauler), forwarders might not be willing to adopt CCFT because they might expect the road haulers to be unwilling to accept it (adaptive expectation effects). This leads to our central proposition:

P.5: In the case of transport subcontracting, forwarders are less willing to shift

to combined transport than in the case of the own fleet disposition

In the next Section, the data collection methodology and the research context are discussed.

\section{Research design and research context}

\subsection{Data collection}

There are relatively few studies devoted to path dependence, where the most prominent methodological approach is the case-study design (Sydow et al. 2012). Hence, including quantitative analysis in the research process may enhance the validity and significance of the conclusions (Sydow et al. 2012). Consistent with the proposition of counterfactual investigations (Vergne and Durand 2010) advocated by the authors, we "test" the path dependence of two different groups of forwarders based on the quantitative data derived from web-based questionnaires, thus enabling inquiry into causal relationships. Furthermore, according to Sydow et al. (2012), the exploration of the interactions between the technological and the organizational paths is considered to be valuable for further research. In our case, the initial investment in semi-trailers, which are not suitable for conventional CCFT, has led to the technological path adopted by companies, which, in turn, may have influenced the organizational set of routines to not consider CCFT in the choice set.

In the first step, a literature review on the initial situation of the CCFT via horizontal transshipment technologies in Germany was conducted. This review serves as the research context of the present contribution. In the framework of the literature review, two different disposition forms were revealed, which resulted in the development of the foundation for this research guided by the theory of organizational path dependence presented in the previous Section. In addition, a set of factors that influence the transport mode decision of forwarders was identified. In addition to traditional factors, such as transport cost, transport time and transport reliability, which according to Cullinane and Toy (2000) are the most frequently studied parameters in the transportation literature, a large number of additional factors (e.g., flexibility and infrastructure availability) affect the transport mode choice (Cullinane and Toy 2000). Subsequently, a pre-test was administered to forwarders and road haulers to ensure the face validity of both questionnaires (Schmoltzi and Wallenburg 2012). Then, two web-based surveys were conducted. The target group of the first questionnaire was composed of forwarders, whom we assume to be the decision makers in the choice of transport mode (see Sect. 2.1). Their key role in the disposition of semi-trailers is thoroughly explained in the 
following Section. The second questionnaire was administered to road haulers, who often operate as subcontractors for forwarders.

During the pre-test with forwarders and road haulers, the face validity of both questionnaires was assessed. Based on the internal database, we then selected 15 forwarder companies and 10 road-hauler companies from various regions in Germany. The selection of forwarders was performed based on the following criteria: company size (European Commission 2005), headquarter location and availability of non-liftable semi-trailers in the fleet. According to the classification of small- and medium-sized enterprises proposed by the European Commission, we selected six companies classified as small-sized forwarder companies $\quad<50$ employees) and six companies classified as medium-sized (50-249 employees). Additionally, three forwarders were large-sized companies ( $>250$ employees). By building the pre-test sample, we attempted to maintain the allocation of the forwarder's market structure as presented in the latest survey of German Freight Forwarders and Logistics Operators (The Association of German Freight Forwarders and Logistics Operators 2010). The pre-test was administered to key informants (Phillips and Bagozzi 1986), specifically to senior managers in the forwarder companies, who are supposedly the most knowledgeable authorities with respect to strategic mode choice decision making. Each of the 15 selected forwarders was first contacted by phone to determine the potential willingness to participate in the pretest. For small- and medium-sized companies, managing directors were contacted. The contact persons of the large forwarder companies were usually the heads of departments. Each of the 15 contacted persons expressed a willingness to participate in the pre-test. An Internet link to the questionnaire was then sent to those who agreed to participate via e-mail. Then, the forwarders answered the questions and provided their personal feedback to the questions in a special "pop-up" window. This qualitative feedback allowed for us to adjust the questionnaire to ensure a common understanding of the quantitative items.

Based on an internal database of an international logistics service provider (total 2011 turnover: 19.8 bn. Euros; 96,000 employees worldwide) the road haulers were selected based on following criteria: number of employees, which was nine or fewer for all the selected companies [because of their dominance in the transport market (see Sect. 3.2)]; operating in full-time as subcontractor of a forwarder; availability of non-liftable semi-trailers in its own fleet. The contact approach for the pre-test among road haulers was identical to that of the approach for forwarders. Among the contacted persons, all of whom were directors of companies, seven were willing to participate in the pre-test. Subsequently, the pre-test administered to the road haulers allowed us to adjust the questionnaire and to derive a common understanding of the items to be used in the web-based questionnaire. The administration of the pre-tests to forwarders and road haulers was performed in January 2011.

The sampling of the first questionnaire was performed using the "Wer liefert was?" ("Who supplies what?") freeware database, which includes the contact data of various sized forwarder companies located in Germany. Out of this database, we identified 1,300 e-mail addresses of key informants-managers at executive levels such as CEOs or managing directors. In addition, the questionnaire was announced 
by trade associations such as the Association of German Freight Forwarders and Logistics Operators (DSLV), German Logistics Association (BVL) and the trade journal DVZ. The web-based questionnaire was conducted in February and March of 2011. We used the Unipark survey tool—a program used by more than 300 universities worldwide-for the question design and the collection of responses. The e-mail invitations were then sent to the sample members. Each respondent received an Internet link to the questionnaire, which allowed him to skip a question or pause and continue answering at any time. In contrast, the link pasted in the announcements of the trade associations did not allow for this feature. A total of 85 companies replied during the first 4 weeks. After the second mailing, an additional 63 usable surveys were received. The public announcements delivered another 15 usable responses. In all, we received 163 responses, for a response rate of $11.3 \%$.

The questionnaire consisted of two main sections. First, forwarders had to answer questions regarding the general characteristics of the company (turnover, number of employees, industries being served). This section of the questionnaire also included questions about the company's fleet (number of liftable and non-liftable semitrailers, allocation of semi-trailers to disposition form-own or foreign semi-trailer as an average share of all semi-trailers). At the beginning of the second section, respondents were asked to identify the prevailing disposition form in the company (self-fulfilling vs. subcontracting). Next, the respondents were presented with a set of so-called "must-have-conditions" regarding the following question to the decision making: transport network-the major company's relations can be served by CCFT; shipment temperature tracking; high transportation safety (no loss and damage); return loads; CCFT flexibility level is comparable with RFT; shipmentfull truck load; and transport unit: non-liftable semi-trailer. With this research design, we attempted to decrease the impact of the unobservable factors on the decision making. Thereafter, respondents were asked whether the company would be willing to shift a significant amount of its own semi-trailers from road to combined transport if the competitive advantage of combined transport was given. The term "competitive advantage" was expressed as "if certain conditions in terms of transport cost and transport quality are given" because these factors are considered to be the most essential in the transport mode choice (Cullinane and Toy 2000). If subcontracting was the prevailing disposition form, we asked whether the respondent's company would be willing to shift a significant amount of the semitrailers of subcontractors under the assumption that the competitive advantage of combined transport would be given. Consequently, the data for the central hypothesis (P.5) were derived from this question.

The sampling of the second questionnaire was performed using the Markus database, which represents companies that produce approximately $95 \%$ of Germany's GNP (Bau and Dowling 2007). This database contains information regarding more than 750,000 companies located in Germany and Austria (Schneider et al. 2007). Additionally, the road hauler database of one international logistics service provider was used. We used the number of employees (maximum 9) as the selection criterion for filtering the small road hauler companies. Based on both databases, 1,000 e-mails of road haulers located in Germany were identified. Using the Unipark tool, the road haulers were surveyed in a manner consistent with that of 
the questionnaire administered to the forwarders. Accordingly, two e-mail invitations were sent, which resulted in 77 usable responses for a response rate of $7.7 \%$.

The questionnaire administered to road haulers consisted of two sections. The first section gathered information about the company's general characteristics. These questions were similar to those asked of the forwarder companies. The second section was dedicated to the road haulers' attitudes towards operating in the combined transport chain. Here, questions regarding the shift from long distance to operations in the pre- or post-carriage (propositions 1 through 4 ) were asked. For all questions, the same 5-point Likert scale was used.

In the following, the results of the observation of the initial situation for CCFT via horizontal transshipment technologies in Germany are presented.

\subsection{Initial situation for CCFT via horizontal transshipment technologies in Germany}

Upon examining the vehicle types owned by the transport industry (see Fig. 1, left), one can see that tractors with semi-trailers dominate the fleet of transport companies. With a total number of 200,950 semi-trailers registered by German transport companies, the transport industry also possesses approximately $81.5 \%$ of the total number of semi-trailers in Germany (Federal Office for Goods Transport 2011a). The road transport market is highly fragmented. Of all the transport companies in Germany, $72 \%$ have 9 or fewer employees. Only $4 \%$ of companies with more than 50 employees can be classified as medium- or large-sized (Federal Office for Goods Transport 2012). The majority of the semi-trailers are owned by small-sized transport companies (up to 49 employees). These companies own $61 \%$ of all semi-trailers in the transport industry (see Fig. 1, right) and often act as subcontractors for forwarders. Of 49,676 companies in the transport sector in 2010 in Germany (Federal Office for Goods Transport 2012), only 8,485 were classified as forwarders (Federal Statistical Office 2007). Therefore, the rest can be classified as road haulers, whose significant role as subcontractors becomes evident at this
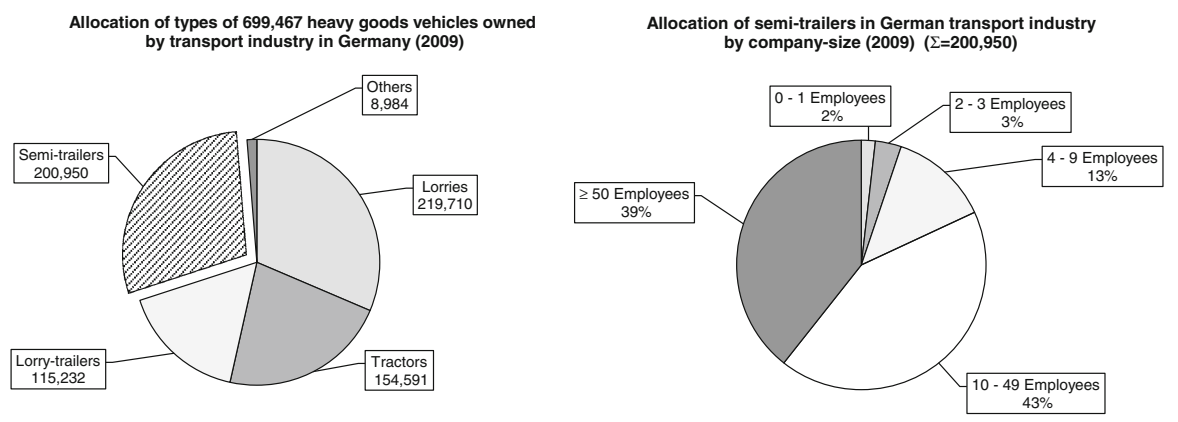

Fig. 1 Vehicle fleet structure in the German transport industry [diagram on the left (Federal Office for Goods Transport 2011a)] and allocation of semi-trailers by company size in the German transport industry in 2009 [diagram on the right (Federal Office for Goods Transport 2011b)] 
point. Approximately $80 \%$ of the transport volume in Germany is disposed by forwarders (The Association of German Freight Forwarders and Logistics Operators 2010), while $76 \%$ of German forwarders, in addition to using their own fleet, also contract with subcontractors (The Association of German Freight Forwarders and Logistics Operators 2010).

Krajewska and Kopfer (2009) indicated that most freight-forwarding companies reduce the capacity of their own vehicle fleet far under the varying total demand limit. To obtain sufficient transportation resources to accommodate the demand, outside carriers are employed (Krajewska and Kopfer 2009). The primary reasons for this approach are to control fixed costs and to be able to supply the customer with the transportation service on demand.

Semi-trailers are the transport unit that resulted in approximately $70 \%$ of the total RFT performance in 2011. In turn, RFT remains the dominant transport mode in Germany, accounting for $71 \%$ of the total freight transport performance in 2011 (Federal Statistical Office 2012). Consequently, semi-trailers can be considered a dominant loading unit in Germany. The majority of these semi-trailers are nonliftable (approximately $95 \%$ ), and therefore, they could not be addressed in the modal shift strategies until new horizontal transshipment solutions emerged. The modal shift from road transport to other freight transport modes is considered as the most critical action for accomplishing sustainable transport (Tsamboulas et al. 2007). Against this background, several policies and incentives on the international (White Paper of the European Commission) and national levels (e.g., Germany's Freight Traffic and Logistics Master Plan) are planned or are already in use to promote CCFT. Although CCFT has been considered a prospective competitor to RFT for medium and long distances, its developments to date have not confirmed such expectations (Janic 2008).

Encouraged by the current transport policy objectives of the European Union, an increasing number of technological solutions for the transshipment of the nonliftable semi-trailers from road to rail have emerged in recent years (e.g., CargoBeamer $^{\circledR}$, Modalohr or Megaswing ${ }^{\mathrm{TM}}$ ). In contrast to the rolling road (RoLa) system operating in Alpine corridors, where the train can only be loaded and unloaded according to the FIFO (first-in-first-out) procedure through using the rollon/roll-off technique (Chiara et al. 2008), these systems rely on rotating or sliding wagon elements, thus offering the possibility of the simultaneous loading and unloading of the semi-trailers (Heidmeier and Siegmann 2008:754). As a consequence, these solutions indicate that CCFT is available for the non-liftable semi-trailers by shifting them horizontally from road to rail wagon and vice versa. Therefore, such solutions maybe powerful enablers for the modal shift from road to rail. The solution providers emphasize in their marketing activities the huge number of non-liftable semi-trailers in Europe as a market potential for their new technologies. However, it is questionable whether the elimination of the access barrier to combined transport would be sufficient to result a forwarder's decision to shift the transport mode.

The strong road transport market fragmentation, with its dominance in smallsized transport companies owning the majority of semi-trailers and acting as subcontractors of forwarders, is evident. Hence, when investigating the market 
prospects of the horizontal transshipment technologies, the specifics of the demand side, in particular, that of the most prominent disposition form, i.e., subcontracting, must be considered. Due to the long-term character of the partnerships, which are common for road-based networks, the established organizational routines between forwarder and road hauler may hinder the willingness to shift the transport mode for both parties. Accordingly, the question of the subcontractors' willingness to adhere to the new rules, their negotiating power and the possible outcomes for their own company after the modal shift can inform them of the origin of potential organizational barriers to the modal shift.

\section{Results and findings}

\subsection{Empirical results}

The sample of forwarders who responded to the questionnaire is dominated by small- and medium-sized forwarder companies (approximately $80 \%$ of the recipients with a maximum of 250 employees and a maximum of 50 Mio. $€$ turnover in 2009). For company size, we use the classification of small- and medium-sized enterprises proposed by the European Commission (European Commission 2005). The sample allocation is, consequently, consistent with the forwarder's market structure presented in the latest survey of German Freight Forwarders and Logistics Operators (The Association of German Freight Forwarders and Logistics Operators 2010). The total number of semi-trailers in the sample is 28,109 [13.9\% of all semi-trailers registered by German transport companies (Federal Office for Goods Transport 2011b)] of which $2 \%$ are liftable. The majority of semi-trailers in the sample (approximately $95 \%)$ are disposed by large- $(>250$ employees) and middle-sized companies (50-250 employees). Subcontracting represents the dominant disposition form among forwarders, with $68 \%$ of all semitrailers in the sample. The differences in the disposition form in dependence on company size are revealed. Large enterprises ( $>250$ employees) dispose $60 \%$ by means of subcontracting and possess $56 \%$ of all semi-trailers in the sample. Middle-sized forwarder companies, $36 \%$ of the companies in the sample with $39 \%$ of all semi-trailers, dispose semi-trailers mainly by means of subcontracting, $85 \%$ are subcontracted semi-trailers and $15 \%$ are from their own fleet. In contrast, smallsized forwarders dispose more of their own semi-trailers than foreign semi-trailers. The share of their own fleet, among the smallest of enterprises ( $<10$ employees), is approximately $60 \%$, while this share is $46 \%$ for small enterprises (10-50 employees). In total, the small-sized forwarder companies dispose only $4.8 \%$ of all semi-trailers in the sample. It should be noted that semi-trailers could be counted twice in the sample. For example, when a large-sized forwarder company disposes the semi-trailer of a small-sized forwarder where both companies are in the sample, the semi-trailer is counted twice. That is, it counts once as being subcontracted for the large-sized forwarder and counts again as being part of the fleet disposition for the small-sized forwarder. 
Table 1 Willingness to switch the mode for both disposition forms when the competition advantage of combined transport is given (central proposition P.5)

\begin{tabular}{lllllll}
\hline Item & Mean & $\begin{array}{l}\text { Standard } \\
\text { deviation }\end{array}$ & $\begin{array}{l}\text { No. of } \\
\text { observations } \\
(1-5)\end{array}$ & $\begin{array}{l}\text { Strongly disagree/ } \\
\text { disagree }(\%)\end{array}$ & $\begin{array}{l}\text { Neutral } \\
(\%)\end{array}$ & $\begin{array}{l}\text { Strongly } \\
\text { agree/agree } \\
(\%)\end{array}$ \\
\hline Self-fulfilling & 3.07 & 1.15 & 92 & 28 & 35 & 37 \\
Subcontracting & 2.68 & 0.88 & 45 & 38 & 44 & 18 \\
\hline
\end{tabular}

Table $2 t$ test results of the central proposition P.5

\begin{tabular}{lllll}
\hline No. & Dependent variable & $t$ & $p$ & Finding \\
\hline$P .5$ & Willingness to switch the mode & 2.007 & 0.047 & Supported* $^{*}$ \\
\hline
\end{tabular}

* Significant at $\alpha=0.05$

As predicted, the willingness to switch the mode from road to combined transport is lower when the forwarder disposes the semi-trailer by means of subcontracting (proposition P.5, see Table 1). The high percentage (44\%) of respondents with a neutral approach towards combined transport can also be identified. Furthermore, there are no respondents who strongly agree to shift the mode. Despite the competitive advantage of combined transport, the willingness to shift the mode is still moderate for both disposition forms. However, when their own semi-trailer is disposed, respondents demonstrate a higher willingness to choose the combined transport. Further analysis by company size revealed a positive correlation between company size and the willingness to switch mode. Large- (mean $=3.35$, $\mathrm{SD}=0.71$ ) and middle-sized forwarders (mean $=3.23, \mathrm{SD}=1.11$ ) were more attracted by the combined transport than the small forwarders (mean $=2.51$, $\mathrm{SD}=1.10)$.

The H0 for the $t$ test of P.5, which was the central proposition of our study, was defined as follows: There is no difference between the means of the both disposition forms $(\mathrm{H} 0: \mu 1=\mu 2)$. The $\mathrm{H} 1$ was then expressed as: $\mu 1 \neq \mu 2$. One can see the differences in the means of the both disposition forms in Table 1. The $t$ test results presented in Table 2 support the $\mathrm{H} 1$ at $5 \%$ confidence level. Based on the results of the Levene's test ( $F$ test: $1,768, p$ value: 0,186$)$ we applied the $t$ test for equal variances. Following, the central proposition can be supported.

To validate the $t$ test results, a Chi square test was additionally conducted. Accordingly, the answers of forwarders who were neutral in their decisions (grade 3 on the Likert scale) were excluded. Furthermore, the answers "strongly disagree" to "disagree" and "strongly agree" to "agree" were bundled for methodological reasons. In the first step, the $2 \times 2$ contingency table was set up (see Table 6). The probability that a forwarder shift to CCFT is $49.4 \%$ (see Table 6 , the total value in the row "\% within disposition model" in the "willingness is given"). Given the specific case, the willingness to switch the mode is independent of the disposition form, the probability of the mode choice within the disposition form would be 50 to $50 \%$. Considering the previous line, it can be found that forwarders with their own 
Table 3 Chi square test results of the central proposition P.5

\begin{tabular}{lllll}
\hline & Value & $d f$ & Asymp. Sig. (two-sided) & Exact Sig. (two-sided) \\
\hline $\begin{array}{l}\text { Pearson } \chi^{2} \\
\text { Fisher exact test }\end{array}$ & $4.614^{\mathrm{a}}$ & 1 & 0.032 & 0.048 \\
$N$ of valid cases & 81 & & & \\
\hline
\end{tabular}

The minimum expected count is 11.4

a 0 cells $(0 \%)$ have an expected count $<5$

Table 4 Symmetric measures

\begin{tabular}{llll}
\hline & & Value & Approx. Sig. \\
\hline Nominal by nominal & Phi & 0.24 & 0.03 \\
& Cramer's V & 0.24 & 0.03 \\
N of valid cases & & 81 & \\
\hline
\end{tabular}

fleet would switch the mode when the probability of $56.9 \%$. Forwarders with subcontracting would select the CCFT with a probability of $30.4 \%$. The assymetric distribution between the both disposition forms can be detected. The asymmetry suggests that there is a correlation between the willingness to switch the mode and the disposition form of the company. That is, the forwarders that primarily dispose the own fleet are more willing to switch to CCFT than forwarders who dispose via subcontracting.

Also a positive value of the standardized residual (0.8) indicates that fewer forwarders with their own fleet were expected, as is observed. In the disposition form "subcontracting", there are more forwarders expected than actually observed $(-1.3)$. Here, the deviations are higher than in the disposition form "self-fulfilling". The values of residuals suggest an existence of the relationship between the willingness to switch to CCFT and the disposition form. Accordingly, H0 and H1 were formulated. $\mathrm{H} 0$ states that the willingness to switch the mode to CCFT is independent of the disposition form of the company $\left(\chi^{2}=0\right)$. H1 states that he willingness to switch the mode to CCFT is dependent of the disposition form of the company $\left(\chi^{2}>0\right)$. Table 3 shows the results of the Chi squared test.

Table 5 General attitude of road haulers to the operations in the combined transport

\begin{tabular}{lllllll}
\hline Proposition & Mean & $\begin{array}{l}\text { Standard } \\
\text { deviation }\end{array}$ & $\begin{array}{l}\text { No. of } \\
\text { observations } \\
(1-5)\end{array}$ & $\begin{array}{l}\text { Strongly disagree/ } \\
\text { disagree }(\%)\end{array}$ & $\begin{array}{l}\text { Neutral } \\
(\%)\end{array}$ & $\begin{array}{l}\text { Strongly agree/ } \\
\text { agree }(\%)\end{array}$ \\
\hline P.1 & 3.16 & 1.31 & 67 & 28 & 24 & 48 \\
P.2 & 3.32 & 1.24 & 68 & 22 & 28 & 50 \\
P.3 & 1.89 & 0.98 & 64 & 75 & 16 & 9 \\
P.4 & 2.21 & 1.34 & 64 & 61 & 19 & 21 \\
\hline
\end{tabular}


At the $5 \%$ confidence level, $\mathrm{H} 0$ is rejected, and the alternative hypothesis, $\mathrm{H} 1$, is supported. The result of the exact Fisher test also supports the alternative hypothesis, H1. This is supported by the Phi-coefficient and Cramer's V values (see Table 4).

Hence, we can suggest that the data analysis supports the central proposition of our paper. That is, in the case of transport subcontracting, forwarders are less willing to switch to combined transport compared to the disposition of their own fleet.

The sample questionnaire for road haulers is dominated by small-sized companies due to the defined selection criteria (maximum of 9 employees). Half of respondents have a maximum of five employees, and $90 \%$ of the companies generated turnover less than 2 million $€$ in 2009. On average, among all road haulers, $60 \%$ of the annual turnover is generated via contracts with forwarders. The remaining $40 \%$ is achieved via direct contracts with shippers.

In the second section of the questionnaire, we explored the general attitude toward the change in the business model from long distances to operations in the pre- or post-carriage. Approximately $50 \%$ of respondents would shift the business model if the forwarder expected this behavior from the road hauler (P.1). Half of the respondents $(50 \%)$ demonstrated low negotiation power (P.2), and the majority of respondents did not support the fleet strategies (P.3 and P.4). These results are shown in Table 5.

\subsection{Discussion}

The general finding of our study is that transport subcontracting could be considered to be a barrier to modal shift from RFT to CCFT. The empirical data support our central hypothesis (proposition P.5). That is, the current disposition form influences the willingness to switch to combined transport. More precisely, forwarders who hire subcontractors (road haulers) in the road freight transport are less willing to switch to CCFT even if the competitive advantage of the CCFT is given (mean selffulfilling $=3.07$, mean subcontracting $=2,68, p<0.05$ ). However, even in the case of self-fulfilling, the willingness to shift the mode is still moderate as only $37 \%$ of the respondents would shift the semi-trailers to CCFT. In both cases, a significant number of decision makers who are neutral in their decision can be registered (35\% in self-fulfilling, $44 \%$ in subcontracting). The results demonstrate that the elimination of the access barrier to combined transport through the introduction of the horizontal transshipment technologies will not "automatically" lead to a mode shift by forwarders in favor of CCFT. In the case of Germany, with $61 \%$ of all semi-trailers in the transport industry owned by the small road haulers companies' who often operate as subcontractors for forwarders, it becomes feasible that the market potential for combined transport with new technologies decreases significantly. It further seems that companies, independent of the disposition form are "locked" into road transport. This finding, however, is not as evident in the cases where road transport is self-fulfilled.

As a possible foundation for the interpretation of the transport mode choice on the part of forwarders, the theory of organizational path dependence was adopted. 
The companies' initial investments into the fleet of the non-liftable semi-trailers have excluded the alternative decision paths such as CCFT from the beginning. The positive feedback from the self-reinforcing mechanisms, such as coordination and learning effects, stimulated the development of the core competence in the RFT and decreased the probability of CCFT in the choice set of forwarders. In the case of subcontracting, the additional coordination expenditures for the forwarder seem to cause the decrease in the willingness to use CCFT. Moreover, the adaptive expectation effects can also be considered as an additional driver for the willingness of the forwarders (with the disposition form "subcontracting") to shift the transport mode. That is, as a consequence of additional or new coordination rules, which result from the shift of the transport mode to CCFT, forwarders might not be willing to adopt CCFT because they expect the road haulers to be unwilling to follow the new rules. Therefore, regardless of CCFT's possible competitive advantage in cost and quality, the forwarders appear to be inert to make the mode shift decision.

As discussed above, the initial investments in the fleet of non-liftable semitrailers restricted the choice of alternative paths, such as CCFT. An alternative to non-liftable semi-trailers could be an investment in containers or swap bodies, which can be used in both RFT and CCFT. Therefore, the investment decision of the forwarders can be considered to be a "critical juncture", which triggers the dynamics of a self-reinforcing process (Sydow et al. 2009). Once a decision is made, the technological lock-in has occurred. Over time, forwarders have adopted a set of routines to increase the coordination efficiency between the participating actors (the forwarder and the road hauler), and they have acquired know-how in the RFT transport area, as evidenced by the positive feedback from the learning effects. Thus, a set of activity patterns become predominant and embedded in an organization (Sydow et al. 2009), resulting in organizational path dependence. Therefore, the technological lock-in could be viewed as a "trigger" for the formation of the organizational path.

The empirical data support the network inertia thesis. Nevertheless, we find that the larger the company, the more attractive CCFT becomes. This finding, however, is not consistent with the proposition of Kim et al. (2006), who argue that larger organizations are less inclined to change their network structure because of increased investment in specific structures and institutionalized routines. In addition, Kim et al. (2006) propose that the longer the duration of an organization's network ties, the less likely the organization is to change those relationships. This proposition is consistent with the work of Knemeyer et al. (2003), who find that long-term partnerships result in increased investments and greater dependence on network partners. Furthermore, Wilson (1995) argues that the existence of investment (e.g., knowledge transfer) creates hesitancy within parties to terminate the relationship. Hence, we can suppose that the large- and medium-sized forwarder companies in our sample have less integrated relationships with subcontractors than do the smaller forwarders. It is remarkable that approximately half of the subcontractors of forwarders would be ready to switch their operations to CCFT (proposition P1). This result did not meet our expectation, as we considered that, due to the additional coordination rules, the road haulers would demonstrate a decreased willingness to shift operations from long distance to pre- or post-carriage. 
The low level of negotiation power (proposition P2) maybe a reason for this attitude. Due to the strong road transport market fragmentation with a dominance of small-sized transport companies, as presented in sub-Sect. 3.2, it can be suggested that forwarders, as buyers of the transport service, possess strong negotiation power relative to road haulers. According to Cox (2001), in this situation, the position of the supplier is characterized by his high dependence on the buyer for revenue with limited alternatives, high switching costs for the supplier, and the commoditized and standardized supplier offerings. Regardless of the high number of road haulers willing to change their business model, the majority of respondents would not entrust other companies with the operation of their semi-trailers and also would not use a pool of semi-trailers (P3 and P4). Thus, there is a strong commitment for road haulers to retain their own semi-trailers. Unfortunately, we could not find other publications that address the question of a firm's dependence on their own fleet in connection with a change in the business model. Thus, we cannot claim that our findings are consistent with any extant literature. Thus, a dilemma exists: On the one hand, road haulers would shift to combined transport operations, but on the other hand, they would not "share" their semi-trailers with other companies. This dilemma should be addressed by forwarders through the development of accordant incentives for subcontractors. Accordingly, such solutions should increase the attractiveness of operations in pre- or post-carriage for road haulers and also address semi-trailer ownership issues.

Finally, the legitimacy for the adaptation of the theory of organizational path dependence perspective for the interpretation of the results must be addressed. It is argued that the use of path dependence theory in the empirical research should be rigorous and cautious, where certain steps regarding the development of the robust hypothesis about the possible presence of path dependence should be considered (Vergne and Durand 2010). In this case, the empirical results of the study allow us to conclude that a given process could be considered to be path dependent (Vergne and Durand 2011). The recommended steps include (1) stipulate the relevant properties of institutions, technologies, or capabilities that should be considered when comparing alternative paths; (2) identify the crucial contingencies that occurred; and (3) specify for each path what components of self-reinforcement are at play (Vergne and Durand 2011). In our study, we first stipulated the two possible disposition forms of forwarders. According to Arthur (1989), contingency means that early in the adoption process, approximately 'twenty adoptions of B in a row' occur, thus giving $\mathrm{B}$ a definitive advantage over $\mathrm{A}$. In our case, the initial investments into the fleet of non-liftable semi-trailers can be considered such an event. Finally, the self-reinforcement mechanisms that primarily stimulate the lockin in the RFT were discussed. In addition, in the case of RFT, we examined the lower-velocity environment, an environment in which the exogenous shocks are less common than they are in high-velocity environments, and hence, a path dependence is more readily observable (Vergne and Durand 2011).

In addition, to decrease the impact of the unobservable factors on the decision making, we assumed a set of "must-have-conditions"-additional factors that influence forwarders in the mode choice-as presented in our questionnaire (see also Sect. 3.1). Despite CCFT's competitive advantage and the given conditions for 
decision making, a significant degree of inertness in the forwarders with respect to modal shift is detected. Against this background, we believe that the study results can be considered from the perspective of path dependence theory. However, because we did not ask the forwarders directly regarding the importance of the three self-reinforcing social mechanisms, we cannot derive the individual level of importance of each mechanism with respect to the decision making.

\section{Conclusion}

The described developments in government transport policy that pays high attention to the modal shift from road to rail, suggest that the sophisticated horizontal transshipment technologies will receive greater attention from the decision makers such as governmental officials and logistics service providers in the coming years. Therefore, for the configuration of the investment and transport policies, it is essential to be aware of the high transport market fragmentation and, as a result, to be aware of the negative impact of subcontracting on the modal shift. In this same context, large-sized forwarder companies with their own fleets may be considered as primary target group for the modal shift from road to rail. For smaller forwarders, which seem to be more locked into road transport, it will take a significant amount of time to break the path and to migrate to the new transport alternative. Here, it should be noted that the forwarder's decision to use CCFT most likely will not be dependent on the availability of specific horizontal transshipment technology alone. The role of other factors-for example, CCFT's performance capability in competition with RFT, company size, the current disposition form of the semitrailer (self-fulfilling or subcontracting) and the fleet strategies of the road haulersinfluence an organization's willingness to shift transport mode. Moreover, the know-how in the inter-organizational network (the alliance capability), particularly the competence in organizing for CCFT, affects this decision. Overall, "network inertia" (Kim et al. 2006) - a barrier to modal shift-appears to exist among the decision makers, which is explained by organizational path dependence. That is, the factors of inter-organizational networks in the road transport, specifically in the forwarder-road hauler relationship, which we list above, can be considered to be barriers to the modal shift from road to rail. Hence, we can suppose that the mere introduction of the horizontal transshipment technologies will not result in shifting a large number of non-liftable semi-trailers to the gates of intermodal terminals. Against the background of the illustrated additional factors, the possibility to use the combined transport may not be considered as an exogenous shock, a factor that is required to "shake the system free of its history" (Vergne and Durand 2010).

The major contribution of this paper to the literature is that it provides an empirical investigation into building of organizational paths demonstrated through a current real-world application in the road freight transport market. In particular, this paper informs the path dependence in inter-organizational relations, which are also likely to become path dependent and which also still await elaboration (Sydow et al. 2009). Following the call of Vergne and Durand (2010), we conducted a counterfactual investigation between two groups of decision makers and "tested" 
organizational path dependence. Furthermore, incorporating quantitative analysis enabled us to ensure the validity and significance of the results of our research (Sydow et al. 2012).

Four notable limitations in our research must be considered. First, the sample frame of both questionnaires consisted only of German-based firms. Accordingly, in our opinion, it would be valuable to extend the scope of this research to other regions and analyze the differences in the impact of the disposition forms by geographical settings. Second, we have only administered the road hauler questionnaire to companies with nine or fewer employees because of their predominance (72\% of all companies) in the transport market. However, only $18 \%$ of all semi-trailers are allocated to these companies, whereas $43 \%$ of semi-trailers are allocated to companies with 10-49 employees. Thus, we perceive a clear need to investigate the behavior of the segment that owns the majority of the semi-trailers. Third, semi-trailers may have been counted twice in the sample. This was the case when, for example, a large forwarder company disposes the semi-trailer of a smallsized forwarder in our sample. Fourth, we did not ask for the partnership duration in the case of subcontracting. Hence, we cannot verify whether large companies have, in general, shorter relationships with subcontractors than do smaller companies and, therefore, are more likely to shift transport mode. Despite these limitations, our work provides important insights regarding the impact of demand side heterogeneity on the modal shift. We consider our work as part of the demand-driven modal shift studies, which, when compared to the supply focused works, are still underrepresented in the research (Tsamboulas et al. 2007). We also hope that our study promotes an interest for further empirical investigations of technological and organizational path dependence and their interactions in real-world applications.

In addition to considering the impact of the geographical setting on the organizational path dependence for the investigated research question, future research may also be extended to similar problems such as new alternatives in the choice set through technological innovations in other industries. Similar to Sydow et al. (2012), we propose that considering the interaction of technological and organizational path dependence on producing an outcome may deliver intriguing results. In this context, a further clarification of the interrelationship between technological and organizational path dependence would be needed and could, thus, be an avenue for future research in the field of supply and logistics management as well. We encourage future studies, and particularly encourage scholars in the field of transport and logistics to examine whether incentives can be developed by forwarders to increase the attractiveness of the combined transport operations for road haulers.

Acknowledgments The authors are grateful to the referees for their suggestions and helpful comments, which enabled us to improve the quality of the study. This study is based on research conducted during the elaboration of the MitKV research project, which was financed by DB Schenker. The authors would like to thank the companies that participated in our survey. Additionally, the authors would like to acknowledge the indispensible support of Michael Kadow, Dr. Dogan Özgen, Alexander Borger and Zuzana John. 
Open Access This article is distributed under the terms of the Creative Commons Attribution License which permits any use, distribution, and reproduction in any medium, provided the original author(s) and the source are credited.

\section{Appendix}

See Table 6.

Table 6 Contingency table: Willingness to switch the mode and the disposition form

\begin{tabular}{|c|c|c|c|c|c|}
\hline & & & \multicolumn{2}{|c|}{ Disposition form } & \multirow[t]{2}{*}{ Total } \\
\hline & & & $\begin{array}{l}\text { Self- } \\
\text { fulfilling }\end{array}$ & Subcontracting & \\
\hline \multirow{14}{*}{$\begin{array}{l}\text { Willingness to } \\
\text { switch the mode }\end{array}$} & \multirow{7}{*}{$\begin{array}{l}\text { No } \\
\text { willingness }\end{array}$} & Count & 25 & 16 & 41 \\
\hline & & Expected count & 29.4 & 11.6 & 41.0 \\
\hline & & $\begin{array}{l}\% \text { within willingness to } \\
\text { switch the mode }\end{array}$ & $61.0 \%$ & $39.0 \%$ & $100.0 \%$ \\
\hline & & $\begin{array}{l}\% \text { within the disposition } \\
\text { form }\end{array}$ & $43.1 \%$ & $69.6 \%$ & $50.6 \%$ \\
\hline & & $\%$ of total & $30.9 \%$ & $19.8 \%$ & $50.6 \%$ \\
\hline & & Residual & -4.4 & 4.4 & \\
\hline & & Std. residual & -0.8 & 1.3 & \\
\hline & \multirow{7}{*}{$\begin{array}{l}\text { Willingness } \\
\text { is given }\end{array}$} & Count & 33 & 7 & 40 \\
\hline & & Expected count & 28.6 & 11.4 & 40.0 \\
\hline & & $\begin{array}{l}\% \text { within willingness to } \\
\text { switch the mode }\end{array}$ & $82.5 \%$ & $17.5 \%$ & $100.0 \%$ \\
\hline & & $\begin{array}{l}\% \text { within the disposition } \\
\text { form }\end{array}$ & $56.9 \%$ & $30.4 \%$ & $49.4 \%$ \\
\hline & & $\%$ of total & $40.7 \%$ & $8.6 \%$ & $49.4 \%$ \\
\hline & & Residual & 4.4 & -4.4 & \\
\hline & & Std. Residual & 0.8 & -1.3 & \\
\hline \multirow[t]{5}{*}{ Total } & & Count & 58 & 23 & 81 \\
\hline & & Expected count & 58.0 & 23.0 & 81.0 \\
\hline & & $\begin{array}{l}\% \text { within willingness to } \\
\text { switch the mode }\end{array}$ & $71.6 \%$ & $28.4 \%$ & $100.0 \%$ \\
\hline & & $\begin{array}{l}\% \text { within the disposition } \\
\text { form }\end{array}$ & $100.0 \%$ & $100.0 \%$ & $100.0 \%$ \\
\hline & & $\%$ of total & $71.6 \%$ & $28.4 \%$ & $100.0 \%$ \\
\hline
\end{tabular}

\section{References}

American Trucking Associations. 2012. U.S. Freight Transportation Forecast to 2023, http://www. atabusinesssolutions.com/ATA/ATAProductDetail.aspx?ProductId=1167616 Accessed 12 Nov 2012. 
Anderson, Stephen. 2010. Freight modal choice study. Behavioural barriers and factors influencing modal choice, http://assets.dft.gov.uk/publications/pgr-freight-freight-modal-pdf/behavioural1.pdf Accessed 12 Nov 2012.

Arrow, Kenneth J. 2004. Path dependence and competitive equilibrium, in: Timothy W. Guinnane, William Andrew Sundstrom, and Warren C. Whatley (eds.): History matters. Essays on economic growth, technology, and demographic change. Stanford: Stanford University Press, 23-35.

Arthur, W.Brian. 1994. Increasing returns and path dependency in the economy. Ann Arbor: University of Michigan Press.

Arthur, W.Brian. 1989. Competing technologies, increasing returns and lock-in by historical events. Economic Journal 99(394): 116-131.

Bau, Frank, and Michael Dowling. 2007. An empirical study of reward and incentive systems in German Entrepreneurial Firms. Schmalenbach Business Review 59(2): 160-175.

Behrends, Sönke. 2011. Urban freight transport sustainability. The interaction of urban freight and intermodal transport. Göteborg: Chalmers University of Technology.

Bergantino, Angela Stefania, and Simona Bolis. 2004. An analysis of maritime ro-ro freight transport service attributes through adaptive stated preference: an application to a sample of freight forwarders. European Transport 8(25-26): 33-51.

Beyer, Jürgen. 2010. The same or not the same-on the variety of mechanisms of path dependence. International Journal of Social Sciences 5(1): 1-11.

Bontekoning, Y., C. Macharis, and J.J. Trip. 2004. Is a new applied transportation research field emerging?-A review of intermodal rail-truck freight transport literature. Transportation Research Part A: Policy and Practice 38(1): 1-34.

CargoBeamer (2013): Antworten auf häufig gestellte Fragen, http://www.cargobeamer.com/public/ 796717_Fragen_und_Antworten/ Accessed 23 Apr 2013.

Chiara, Bruno Dalla, Francesco Paolo Deflorio, and Domenico Spione. 2008. The rolling road between the Italian and French Alps: modeling the modal split. Transportation Research Part E: Logistics and Transportation Review 44(6): 1162-1174.

Choong, Sook Tying, Michael Cole, and Erhan Kutanoglu. 2002. Empty container management for intermodal transportation networks. Transportation Research Part E: Logistics and Transportation Review 38(6): 423-438.

Cox, Andrew. 2001. Understanding buyer and supplier power: a framework for procurement and supply competence. The Journal of Supply Chain Management 37(2): 8-15.

Crainic, Teodor Gabriel, and Gilbert Laporte. 1997. Planning models for freight transportation. European Journal of Operational Research 97(3): 409-438.

Cullinane, Kevin, and Neal Toy. 2000. Identifying influential attributes in freight route/mode choice decisions: a content analysis. Transportation Research Part E: Logistics and Transportation Review 36(1): 41-53.

Danielis, Romeo, Edoardo Marcucci, and Lucia Rotaris. 2005. Logistics managers stated preferences for freight service attributes. Transportation Research Part E: Logistics and Transportation Review 41(3): 201-215.

Eng-Larsson, Fredrik, and Christofer Kohn. 2012. Modal shift for greener logistics-the shipper's perspective. International Journal of Physical Distribution \& Logistics Management 42(1): 36-59.

European Commission. 2011. White Paper on transport, http://ec.europa.eu/transport/themes/strategies/ 2011_white_paper_en.htm Accessed 12 Nov 2012.

European Commission. 2005. The new SME definition, http://ec.europa.eu/enterprise/policies/sme/files/ sme_definition/sme_user_guide_en.pdf Accessed 12 Nov 12.

Eurostat. 2011. Freight Transport Statistics, http://epp.eurostat.ec.europa.eu/statistics_explained/index. php/Freight_transport_statistics Accessed 12 Nov 2012.

Federal Ministry of Transport. 2010. Aktionsplan Güterverkehr und Logistik-Logistikinitiative für Deutschland. Berlin: Bundesministerium für Verkehr, Bau und Stadtentwicklung.

Federal Motor Transport Authority. 2012. Verkehr deutscher Lastkraftfahrzeuge-Verkehrsaufkommen, Jahr 2011. Flensburg: Kraftfahrt-Bundesamt

Federal Office for Goods Transport. 2012. Struktur der Unternehmen des gewerblichen Straßengüterverkehrs und des Werkverkehrs. Stand: November 2010. Köln: Bundesamt für Güterverkehr.

Federal Office for Goods Transport. 2011a. Struktur der Unternehmen des gewerblichen Güterkraftverkehrs und des Werkverkehrs. Stand: November 2009. Köln: Bundesamt für Güterverkehr. 
Federal Office for Goods Transport. 2011b. Aufteilung der Sattelauflieger des gewerblichen Güterkraftverkehrs auf die Beschäftigungsklassen, Personnel communication, 04.09.2011. Köln: Bundesamt für Güterverkehr.

Federal Statistical Office. 2012. Modal-Split im deutschen Güterverkehr im Zeitraum von 2007 bis 2012 nach Verkehrsträgern (Anteil an der Verkehrsleistung), http://de.statista.com/statistik/daten/studie/ 12149/umfrage/gueteraufkommen-nach-verkehrstraegern-in-deutschland-seit-1956/ Accessed 04 Dec 2012.

Federal Statistical Office. 2007. Dienstleistungen. Strukturerhebung im Dienstleistungsbereich Verkehr und Nachrichtenübermittlung. Statistisches Bundesamt: Wiesbaden

Feo, Maria, Raquel Espino, and Leandro Garcia. 2011. An stated preference analysis of Spanish freight forwarders modal choice on the south-west Europe Motorway of the Sea. Transportation Research 18(1): 60-67.

Gulati, Ranjay, Nitin Nohria, and Akbar Zaheer. 2000. Strategic Networks. Strategic Management Journal 21(3): 203-215.

Heidmeier, Sven, and Jürgen Siegmann. 2008. Eisenbahngüterverkehr. In Handbuch Logistik, 3rd ed, ed. Dieter Arnold, Heinz Isermann, Axel Kuhn, Horst Tempelmeier, and Kai Furmans, 743-757. Berlin Heidelberg: Springer.

Ishfaq, Rafay, and Charles R. Sox. 2010. Intermodal logistics: the interplay of financial, operational and service issues. Transportation Research Part E: Logistics and Transportation Review 46(6): 926-949.

Janic, Milan. 2008. An assessment of the performance of the European long intermodal freight trains (LIFTS). Transportation Research Part A: Policy and Practice 42(10): 1326-1339.

Janic, Milan. 2007. Modelling the full costs of an intermodal and road freight transport network. Transportation Research Part D: Transport and Environment 12(1): 33-44.

Jurczyk, Andrzej Jan, Herbert Kopfer, and Marta Anna Krajewska. 2006. Speditionelle Auftragsdisposition eines mittelständischen Transportunternehmens. Internationales Verkehrswesen 6: 275-279.

Kaplan, Steven, and Mohanbir Sawhney. 2000. E-hubs: the new B2B (business-to-business) marketplaces. Harvard Business Review 78(3): 97-103.

Khanna, Tarun. 1998. The scope of alliances. Organization Science 9(3): 340-355.

Kim, Tai-Young, Oh Hongseok, and Anand Swaminathan. 2006. Framing interorganizational network change: a network inertia perspective. Academy of Management Review 31(3): 704-720.

Knemeyer, A.Michael, Thomas M. Corsi, and Paul R. Murphy. 2003. Logistics outsourcing relationships: customer perspectives. Journal of Business Logistics 24(1): 77-109.

Koch, Jochen. 2011. Inscribed strategies: exploring the organizational nature of strategic lock-in. Organization Studies 32(3): 337-363.

Krajewska, Marta Anna, and Herbert Kopfer. 2009. Transportation planning in freight forwarding companies: tabu search algorithm for the integrated operational transportation planning problem. European Journal of Operational Research 197(2): 741-751.

Langley, C. John. 2013. Third-Party Logistics Study. The State of Logistics Outsourcing, http://www. 3plstudy.com/downloads/2013-3pl-study/ Accessed 03 Apr 2013.

Leonard-Barton, Dorothy. 1992. Core capabilities and core rigidities: a paradox in managing new product development. Strategic Management Journal 13(S1): 111-126.

Miller, Danny. 1993. The architecture of simplicity. Academy of Management Review 18(1): 116-138.

Nickerson, Jack A., and Brian S. Silverman. 2003. Why aren't all truck drivers owner-operators? Asset ownership and the employment relation in interstate for-hire trucking. Journal of Economics and Management Strategy 12(1): 91-118.

Phillips, Lynn W. and, Richard P. Bagozzi. 1986. On Measuring Organizational Properties of Distribution Channels: Methodological Issues in the Use of Key Informants, in: L. Bucklin and J. M. Carman (eds.): Research in Marketing, 8: 313-369.

Prahalad, C.K., and Gary Hamel. 1990. The core competence of the corporation. Harvard Business Review 68(3): 79-91.

Rich, Jeppe and, Christian Overgaard. 2009. Freight transport trends for 2020, 2030, and 2050.Deliverable 4.3 of FREIGHTVISION-Vision and Action Plans for European Freight Transport until 2050, Funded by the European Commission 7th RTD Programme, Copenhagen, Denmark.

Schmoltzi, Christina, and Carl Marcus Wallenburg. 2012. Operational governance in horizontal cooperations of logistics service providers: performance effects and the moderating role of cooperation complexity. Journal of Supply Chain Management 48(2): 53-74. 
Schmoltzi, Christina, and Carl Marcus Wallenburg. 2011. Horizontal cooperations between logistics service providers: motives, structure, performance. International Journal of Physical Distribution and Logistics Management 41(6): 552-576.

Schneider, Julia K., Michael Dowling, and Sumita Raghuram. 2007. Empowerment as a success factor in start-up companies. Review of Managerial Science 1(2): 167-184.

Schreyögg, Georg, and Jörg Sydow. 2011. Organizational path dependence: a process view. Organization Studies 32(3): 321-335.

Sommar, R. 2006. Long-distance hauliers'transport mode choices. Proceedings of the New Scolars Conference on Sustainable Transportation, www.publications.lib.chalmers.se/records/fulltext/ 22684.pdf Accessed 03 Apr 2013.

Stieglitz, Nils, and Klaus Heine. 2007. Innovations and the role of complementarities in a strategic theory of the firm. Strategic Management Journal 28(1): 1-15.

Sydow, Jörg, Arnold Windeler, Gordon Müller-Seitz, and Knut Lange. 2012. Path constitution analysis: a methodology for understanding path dependence and path creation. Business Research 5(2): 1-22.

Sydow, Jörg, Georg Schreyögg, and Jochen Koch. 2009. Organizational path dependence: opening the black box. Academy of Management Review 34(4): 689-709.

The Association of German Freight Forwarders and Logistics Operators. 2010. Zahlen Daten Fakten aus Spedition und Logistik 2010. Bonn: DSLV.

Transportation Research Board. 1996. Institutional barriers to intermodal transportation policies and planning in metropolitan areas transportation. Washington D.C: National Academy Press.

Tsamboulas, Dimitrios, Huub Vrenken, and Anna-Maria Lekka. 2007. Assessment of a transport policy potential for intermodal mode shift on a European scale. Transportation Research Part A: Policy and Practice 41(8): 715-733.

UN/ECE. 2001. Terminology on Combined Transport. United Nations: New York and Geneva.

Vassallo, Walter, Annalisa Alcinesio, Irina Roussina, Chris Rowland, Tony Morall, Eva Gelova, Ioan Cuncev, Elli Krassopoulou, Csaba Orosz, Dimitar Stoyanov, and Smiljan Vukanovic. 2007. Freight Market Structure and Requirements for Intermodal Shifts, http://freightwise.tec-hh.net/Deliverable_ 11.1_Freight_Market_Structure_and_Requirements_for_Intermodal_Shifts.pdf Accessed 12 Nov 2012.

Vergne, Jean-Philippe, and Rodolphe Durand. 2011. The path of most persistence: an evolutionary perspective on path dependence and dynamic capabilities. Organization Studies 32(3): 365-382.

Vergne, Jean-Philippe, and Rodolphe Durand. 2010. The missing link between the theory and empirics of path dependence: conceptual clarification, testability issue, and methodological implications. Journal of Management Studies 47(4): 736-759.

Walker, Gordon, Bruce Kogut, and Weijian Shan. 1997. Social Capital, Structural Holes and the Formation of an Industry Network. Organization Science 8(2): 109-125.

Warning, Susanne. 2004. Performance differences in German higher education: empirical analysis of strategic groups. Review of Industrial Organization 24(4): 393-408.

Wilson, David T. 1995. An integrated model of buyer-seller relationships. Journal of the Academy of Marketing Science 23(4): 335-345.

Wittenbrink, Paul. 2009. BME-Umfrage: Green-Logistics-hohe Bedeutung auch in Krisenzeiten. Frankfurt/Lörrach: Bundesverband Materialwirtschaft, Einkauf und Logistik.

Woxenius, Johan, and Fredrik Bärthel. 2006. Intermodal Road-Rail Transport in the European Union. In The Future of Intermodal Freight Transport, ed. Rob Konings, Hugo Priemus, and Peter Nijkamp, 13-34. UK: Concepts, Design and Implementation, Cheltenham, Edward Elgar Publishing.

Zinn, Walter, and A. Parasuraman. 1997. Scope and intensity of logistics-based strategic alliances-a conceptual classification and managerial implications. Industrial Marketing Management 26(2): $137-147$. 